\title{
AINDA O SUJEITO - NOTA SOBRE O CONFLITO \\ DETERMINAÇÃO x SUBJETIVIDADE EM JACQUES LACAN ${ }^{1}$
}

\section{Still The Subject - A Note On The Conflict Determination $\mathrm{X}$ Subjectivity in Jacques Lacan}

Léa Silveira Sales ${ }^{2}$

\section{Resumo}

O trabalho descreve, no interior da teoria lacaniana, a operação implícita na definição de sujeito relativa à década de 50 à luz dos redimensionamentos requisitados por um ideal de cientificidade. $\mathrm{O}$ conflito entre determinismo e subjetividade - que bem se traduz no oxímoro "objetivação do sujeito" - , sendo fecundado pela negatividade kojèviana do desejo e pela aspiração estruturalista à formalização, pode ser indicado como um dos motores mais fundamentais dos desenvolvimentos da teoria em questão. A saída vislumbrada para este impasse, que é intrínseco às ciências humanas, é situar a negação no âmago do sujeito, tomando-o, dessa forma, essencialmente inobjetivável, porém ainda formalizável.

Palavras-chave: Teoria lacaniana; Sujeito; Ciência; Estruturalismo; Kojève.

1 Trabalho apresentado no XI Encontro Nacional de Filosofia da ANPOF (18 a 22 de outubro de 2004).

2 Universidade Federal de São Carlos, Centro de Educação e Ciências Humanas. Rodovia Washington Luís, km 235 -Monjolinho13565-905 - São Carlos, SP - Brasil Telefone: (16) 2608368 Fax: (16) 2608368.

E-mail: lea_silveira@uol.com.br

Revista de Filosofia, Curitiba, v. 17 n.20, p. 99-124, jan./jun. 2005. 


\section{Abstract}

The text describes, within Lacanian theory, the implicit operation on the definition of subject concerning the 50's under the focus of the new combination of terms required by an ideal of science. The conflict between determinism and subjectivity - which is efficiently translated by the oxymoron "subject's objectivation" - , being fertilized by Kojevian desire's negativity and by the structuralistaspiration towards formalization, can be indicated as one of the most fundamental engines of the developments of this theory. The solution to this impasse, that is intrinsic to the human sciences, is glimmered through the negation situated at the heart of the subject that is thus converted into something essentially unobjectable, but still formalizable.

Keywords: Lacanian theory; Subject; Science; Sructuralism; Kojève.

"Há tempos observou-se que, em todas as substâncias, o sujeito propriamente dito, aquilo que fica depois de retirados os acidentes (como predicados), portanto o verdadeiro elemento substancial, nos é desconhecido." (Kant, Prolegômenos a toda metafísica futura que queira apresentar-se como ciência, § 46)

\section{Apresentação do problema}

Quando Lacan (1969), ao intervir numa exposição de Foucault diretamente relacionada ao tema da morte do sujeito como palavra de ordem do estruturalismo, expõe que seu interesse dobra-se sobre a questão da dependência do sujeito e não sobre a da sua exclusão, está de fato defendendo o cerne de seu projeto. A psicanálise - como teoria e como prática clínica - não poderia mesmo sobreviver, fizesse coro ao famoso refrão. Porém, se aquela dependência se traduz pela total subsunção da subjetividade a um elemento determinante (o significante), o que resta perguntar é: como pode algo tão determinado continuar a ser chamado de "sujeito"? Esse conflito - que bem se traduz no oxímoro "objetivação do sujeito" -, sendo fecundado pela negatividade kojèviana do desejo e pela aspiração estruturalista à ciência, pode ser indicado como um dos motores mais fundamentais dos desenvolvimentos teóricos da obra em pauta, ao menos durante o período que aqui procuramos destacar. Con-

Revista de Filosofia, Curitiba, v. 17 n.20, p. 99-124, jan./jun. 2005. 
ceitos como Outro, falo, Édipo, pulsão podem ser lidos, no campo lacaniano, como vieses do esforço de fazer dialogarem a ciência e a negação. São instrumentos que contribuem para pensar o sujeito como algo, digamos assim, "desaparecente": uma manifestação do inconsciente que não é aparecendo, que aparece não sendo; uma instância de subjetividade cuja referência a si mesma é de antemão mal-sucedida em razão da ausência de uma essência que lhe fosse pertinente.

Delineia-se aí uma abertura: abandona-se a necessidade de compreender o sujeito (preocupação presente na chamada "teoria do imaginário") para se passar a pô-lo em questão. Trata-se de propor uma sua escuta (não apenas no sentido clínico) e não de explicá-lo (o que seria impossível devido à sua própria natureza e à concepção também paradoxal de conhecimento ${ }^{3}$ ). O sujeito, então, não é mais tratado como objeto. Essa a saída para o impasse intrínseco às ciências humanas: tomar o sujeito como algo inobjetivável e ensaiar paradoxalmente formalizar essa "inobjetivação". Ao se fazer segundo essas diretrizes uma ciência do sujeito, não se corre o risco, por uma questão de definição, de objetivá-lo. Porém, é somente pelo fomento de um novo impasse que 0 primeiro encontra sua ultrapassagem: a formalização pretendida tem como alvo algo que só se presentifica pela negação de si, oscilação que não revela mais do que um ponto ausente que, apesar disso (e por causa disso, dentro da lógica lacaniana), é o local que sustenta a operação do sentido.

Mas, convém questionar, realizar este movimento não implica ameaçar a reserva desse lugar como sendo o de um "sujeito"? Como se constitui a consistência desse nada?E, afinal, por que o sujeito "verdadeiro" (sem o qual a clínica psicanalítica equivaleria a uma prática de sugestão), determinado pelo significante, seria menos alienado que o eu, determinado pela imagem?

\section{Retomando os termos do problema em fases anteriores}

O conflito entre determinação e subjetividade não é prerrogativa da fase estruturalista de Lacan, mas congênito à sua carreira intelectual. Quer atravessasse a psiquiatria, a psicologia ou a psicanálise, quer

${ }^{3}$ A situação do conhecimento na teoria lacaniana será assunto para um outro trabalho.

Revista de Filosofia, Curitiba, v. 17 n.20, p. 99-124, jan./jun. 2005. 
tivesse em vista a necessidade de formular uma causalidade específica para a psicose ou os caminhos que conduzem à neurose, seu empenho, o impulso mesmo para a colocação em jogo dos mais diversos referenciais teóricos já tinha como pano de fundo o projeto de uma ciência do sujeito.

Em sua tese de doutorado - Da psicose paranóica em suas relações com a personalidade (1932) -, o mecanismo que disparava a experiência paranóica era estruturado em torno de três áreas: o desenvolvimento biográfico, a concepção de si e a tensão das relações sociais; esta última representando o ponto de convergência da causalidade (LACAN, 1987, p. 46). Definida a patologia mental como discordância com o meio social $^{4}$, este trabalho seria contraditório, não conservasse espaço para 0 que é considerado próprio da atividade do sujeito pelo modo da reação atualizada na interpretação delirante. Afinal, como explicar que um determinismo social dê lugar a uma incompatibilidade com o social senão assentindo que esse descompasso se deve à especificidade da resposta subjetiva? Assim, o sujeito não é visto como um mero resultado de um arranjo de influências ${ }^{5}$, mas dotado de uma "estrutura reacional". O ponto específico no deslanchamento da psicose encontrava-se, ipso facto, acuado justamente para a face do esquema mais em desacordo com um ideal de cientificidade: o mundo psíquico do sujeito; exigindo que se estipulasse, para o caso patológico, a presença de acontecimentos pontuais, o andamento de reações singulares, os quais, apesar de entrevistos através do crivo do conceito politzeriano de "drama" - portanto, inseridos em um referencial materialista, concreto e determinista - acabavam por impedir que tal enquadramento chegasse a prover uma generalização do modelo.

No final da década de 30, o problema passa a receber outra configuração. Por essa época, e em diálogo com a fenomenologia, 0

4 “O que a interpretação delirante faz, afinal de contas, é construir para o psicótico um Umwelt que não coincide com a representação social da realidade vigente no grupo a que pertence. Esta discordância - mais o fato de que ela não é subjetivamente assimilável como tal, sendo apreendida, por exemplo, na forma persecutória - é o único critério que permite atribuir um caráter patológico a quaisquer destes fenômenos de personalidade." (Simanke, 2002, p. 125-6)

5 Lacan critica as posições extremadas de psicologia científica, “(...) em que o sujeito não é mais nada a não ser o lugar de uma sucessão de sensações, de desejos e de imagens" (1987, p. 24)

Revista de Filosofia, Curitiba, v. 17 n.20, p. 99-124, jan./jun. 2005. 
sujeito é categoria requerida pelo fato da intencionalidade da fala; o discurso é indissociável de um querer dizer: "Somente um sujeito pode compreen der um sentido; inversamente, todo fenômeno de sentido implica um sujeito" (LACAN, 1966, p. 102). Dito de outro modo, o sujeito é deduzido do fato de que toda fala possui uma intenção direcionada à existência de um outro: "Mas o psicanalista, por não desta car a experiência da linguagem da situação que ela implica, a do interlocutor, toca no fato simples de que a linguagem, antes de significar alguma coisa, significa para alguém" (LACAN, 1966, p. 82). O sentido mesmo do discurso é o sujeito em sua faculdade de expressão, que é essencialmente expressão de si mesmo em direção ao seu interlocutor.

Central na teoria do imaginário, é que essa reflexão ocorre em paralelo a uma nova aposta depositada no conceito de imago como o meio para teorizar o surgimento do indivíduo mediante o outro, fazendo da operação de identificação o instrumento de objetivação do ser humano: “A história do sujeito desenvolve-se numa série mais ou menos típica de identificações ideais que representam os mais puros den tre os fenômenos psíquicos no que eles revelam essencialmente a função da imago" (LACAN, 1966, p. 178). A idéia central da teoria do imaginário é a de que as imagens exercem uma função formadora sobre o sujeito e o efeito primeiro dessa formação é o sistema do eu. Por meio da construção conceitual do estágio do espelho, o eu (ainda não diferenciado do sujeito) aparece como movimento de objetivação de uma alienação ${ }^{6}$. Como conseqüência de sua origem na alteridade, temos que o eu não poderá ser senão o lugar da alienação e da ilusão. Essencialmente paranóico, ele é o engodo sintomático a afastar o adjetivo "autêntico" de tudo o que se relacione às características da personalidade e do conhecimento humano ao ponto de ser definido como um sintoma ${ }^{7}$, a psicanálise sendo pensada como um processo equivalente a “(...) induzir no sujeito uma paranóia dirigida” (LACAN, 1966, p. 109).

Nesse novo quadro, o impasse permanece o mesmo: se o que interessa é colocar em jogo o sujeito de modo a impossibilitar sua obje-

6 Essa transição é bem representada, nos termos de Simanke (2002), como a passagem do ponto de vista da "paranóia como fenômeno do conhecimento" ao do "conhecimento como fenômeno paranóico".

7 Isso aparece um pouco mais tarde, em 54 (no Seminário 1, sessão de 13/01/54), fase de diálogo intenso com o estruturalismo, mas na qual essa reflexão sobre o eu permanece.

Revista de Filosofia, Curitiba, v. 17 n.20, p. 99-124, jan./jun. 2005. 
tivação, o eu é incapaz de suprir a demanda, pois, no espelho, reconhece-se apenas a própria imagem como um objeto: "Se o ego é uma função imaginária, não se confunde com o sujeito. $\mathrm{O}$ que é que chamamos um sujeito? Muito precisamente, o que, no desenvolvimento da objetivação, está fora do objeto" (LACAN, 1986, p. 224).

\section{Desenvolvimento: estruturalismo x sujeito + Kojève Do que traz o estruturalismo}

Em 1936, Lacan havia discorrido sobre a convergência da psicologia clássica em torno das idéias de engrama e de ligação associativa, idéias de cunho abstrato, distantes da experiência subjetiva e que subscreviam uma suposição filosófica do psiquismo como substância. Tendo fracassado o programa de pesquisa cristalizado na noção de imago ${ }^{8}$, é preciso, então, efetivar um modo de pensar o funcionamento subjetivo que não se submeta a essa mesma crítica. Nesse novo projeto - que herda a preocupação e a maior parte dos princípios das fases anteriores -, o pólo da determinação é solidário do estruturalismo que, trabalhando o inconsciente como pura forma localizada no concreto do discurso, permite 0 acesso de Lacan a esse conceito tão central na psicanálise e que fora até então desprezado. No pólo da subjetividade, trata-se de continuar manejando o referencial kojèviano - trazido a lume já no artigo sobre os complexos familiares, de 1938, mas que agora vem preencher uma função mais específica ${ }^{9}$.

A convergência entre esses dois referenciais - não obstante se situem nos pontos antinômicos da analítica e da dialética - é viabilizada especialmente pela teoria da linguagem encontrada em ambos. Pois entre o discurso entendido por Kojève como "assassinato da coisa" e como "presença da ausência de uma realidade"10 e a teoria lingüística do valor e da arbitrariedade do signo, não havia mais do que um passo. Lacan

8 Sobre as razões desse fracasso (além da que foi mencionada acima) remeto a Bairrão (2000), e Sales (2003). Acrescentemos apenas que a imago não consegue deixar de ser um conceito substancialista.

9 A ser indicada abaixo, no item 3.3.

10 "(...) 0 entendimento conceitual da realidade empírica é equivalente a um assassinato." (Kojève, 1947, p. 372-3) 
(1966, p. 498) cedo percebeu que dizer que “(...) não há nenhuma significação que se sustente a não ser pela remissão a uma outra significação (...)" era, em termos de conseqüências teóricas, exatamente o mesmo que dizer que um signo só presentifica algo mediante a ausência (ou morte) da coisa à qual ele se refere. Noutros termos, a impossibilidade da linguagem adequar-se às coisas e referir-se apenas a seu próprio sistema é perfeitamente pensável como a negação que o eu exerce sobre 0 não-eu mediante a palavra como desejo, fundando a realidade estritamente como a "Realidade-da-qual-se-fala" (KOJĖVE, 1947, p. 449) ${ }^{11}$.

Tudo muito certo. O problema é que o tipo de formalização avançado pelo estruturalismo e traduzido por Lacan numa extensiva determinação exercida pelo significante sobre o sujeito, reatualiza, desenvolvendo seu clímax, o paradoxo de difícil manuseio acima mencionado. Entre 1953, data do Discurso de Roma, e meados de 1958, época em que começa a surgir a noção de uma "falta no Outro"12, são freqüentes as explorações do tema. A título de alguma exemplificação, citemos apenas, no texto sobre A carta roubada:

Se 0 que Freud descobriu e redescobre de forma cada vez mais abrupta, possui um sentido, é que o deslocamento do significante determina os sujeitos em seus atos, em seus destinos, em suas recusas, em suas cegueiras, em seus sucessos e em suas sortes, não obstante seus dons inatos e seus valores sociais, sem considerar o caráter ou o sexo, e que por bem ou por mal seguirá o caminho do significante, como armas e bagagens, tudo aquilo que é do dado psicológico (LACAN, 1966, p. 30).

11 Borch-Jacobsen (1991a, p. 193) indica essa convergência. Mas, ao fazê-lo, afirma que o estruturalismo só forneceu a Lacan a possibilidade de uma baliza científica a ser confiada a uma filosofia do sujeito preexistente a tal expediente: “(...) esses empréstimos da lingüística estrutural tomam lugar à sombra de uma filosofia do sujeito e da linguagem, que lhes precede, e à qual eles não trazem nada além de um tipo de 'garantia' científica coerciva." (p. 193) Na verdade, isso precisa ser equacionado de outro modo, pois, por um lado, o estruturalismo leva à teoria lacaniana muito mais do que a qualidade científica: leva-lhe, no mesmo ato, o próprio conceito de inconsciente; e, por outro, durante a teoria do imaginário - fase a que Borch-Jacobsen se refere como sendo a precedente -, Lacan ainda não levava às últimas conseqüências a concepção de sujeito como negatividade, procurando inclusive construir uma psicologia, em muito, bastante tradicional.

${ }^{12}$ Retornaremos a esse ponto ao final do artigo no item 3.4.

Revista de Filosofia, Curitiba, v. 17 n.20, p. 99-124, jan./jun. 2005. 
E no segundo ano do Seminário:

No meio (...) do funcionamento da razão, o sujeito se acha desde 0 início da jogada, não sendo mais do que um peão, impelido para dentro desse sistema, e excluído de toda participação que seja propriamente dramática e, por conseguinte trágica, na realização da verdade (LACAN, 1985, p. 214).

Fica muito claro a partir daí que o sujeito é visto como o produto do funcionamento do simbólico. Ele vem apenas ocupar um lugar num jogo que já apresenta suas próprias leis (LACAN, 1985, p. 243). A exposição de A carta roubada não visava a mostrar outra coisa, nem as explorações da cibernética no Seminário 2: o simbólico, cujo fundamento seria a insistência repetitiva, teria efeito de alienação; “(...) ele é causa de o sujeito realizar-se sempre alhures e de sua verdade lhe estar sempre velada em alguma parte" (LACAN, 1985, p. 264).

Ora, se o interesse vital do projeto lacaniano desde seus primórdios é resguardar um sentido do sujeito como sujeito do sentido, não é evidente que a racionalidade estruturalista só pode ser convidada a tomar parte na disputa cum grano salis? Por outro lado, uma aproximação à acepção lévi-straussiana de inconsciente, além de atribuir mão única à via da determinação, exige um tal afastamento da forma como Freud o pensou que não resta espaço para aspectos tão fundamentais de sua teoria como o afeto, por exemplo, e durante bastante tempo, a própria pulsão, só admitida à força da deturpação de seu sentido. Como declara Roustang em entrevista a Dosse (1991/1993): “A operação lacaniana tem que ser dupla, isto é, perfeitamente contraditória. Por uma parte, cumpre-lhe manter a subjetividade, (...) e, por outra esvaziar essa subjetividade de toda encarnação, humanização, afetividade, etc., para fazer dela um objeto matemático” (p. 281). A lingüística traz à psicanálise a perspectiva de uma objetividade que, contudo, tem que ser impedida de resvalar para uma objetalidade. Diga-se a propósito que se o sujeito fosse assim tão determinado pelo significante, a clínica seria uma prática fadada à esterilidade: não poderia pleitear efeito nenhum pois nem analista, nem analisando - como sujeitos que são - teriam como interferir de algum modo nos desígnios cegos dos significantes. Lembremos que, nessa mesma fase da obra de Lacan, o recurso à noção de sujeito é sempre atrelado à idéia de algo capaz de atribuir sentido à multiplicidade da experiência; pelo início do Seminário 2, lemos a seguinte amostra: "Dou-

Revista de Filosofia, Curitiba, v. 17 n.20, p. 99-124, jan./jun. 2005. 
lhes uma definição possível da subjetividade, ao formulá-la como sistema organizado de símbolos que almeja cobrir a totalidade de uma experiência, animá-la, dar-lhe sentido" (1985, p. 58). Assim, não há por que usar meias palavras: sob um uso estritamente estruturalista da linguagem, o sujeito é irrevogavelmente impensável ${ }^{13}$. A não ser que... um dos termos da equação - sujeito e estrutura (ou ambos) - seja repensado. A primeira tentativa de Lacan será reconsiderar o primeiro e os resultados disso serão indispensáveis à teoria, mesmo quando o problema passar a receber outras soluções. E o próprio desenlace deste primeiro passo exigirá a revisão do segundo termo, trazendo a lume uma idéia mais específica de estrutura ${ }^{14}$.

Quais serão, pois, as curvas do itinerário que ensaiará responder como almejar falar do sujeito de um modo que se quer científico sem, ato contínuo, objetivá-lo e, conseqüentemente, perdê-lo de vista?

\section{A passagem por Descartes}

Em 1957, Lacan condensa, numa apresentação dirigida a estudantes de letras, uma reflexão que já vinha desenvolvendo acerca da metáfora e da metonímia entendidas como determinadas relações de substituição ou de deslocamento entre significantes e chamadas a explicarem o verdadeiro sentido e a formalizarem aquilo que Freud denominara "trabalho do sonho". O objetivo é estabelecer uma equivalência entre pensamento inconsciente e estes mecanismos significantes. Nessa conferência, quando se trata de discutir a função do sujeito, a primeira referência é Descartes. O "penso, logo existo" é a garantia da existência de um sujeito suposto ao pensamento que resguarda sua posição subjetiva mesmo quando se ocupa consigo mesmo como objeto: "Talvez eu seja apenas objeto e mecanismo (e, portanto, nada mais que fenômeno), mas, certamente, na medida em que o penso, eu sou - de modo absolu to" (LACAN, 1966, p. 516). Mesmo na ocasião em que penso que eu seja apenas objeto, sou [como sujeito] de modo absoluto porque penso. Isto é, o cogito é exatamente a reflexão capaz não apenas de defender que o sujeito não perde seus distintivos ao se posicionar como objeto de um

13 “O problema dessa segunda etapa [a etapa estruturalista] é que, nela, o sujeito - como sujeito do significante, irredutível ao eu imaginário - é no fundo impensável: de um lado temos o eu imaginário, lugar da cegueira e do desconhecimento, ou seja, o eixo aa'; de outro, um sujeito totalmente assujeitado à estrutura, alienado, sem resto e, nesse sentido, des-subjetivado" (_I_EK, 1991, p. 77).

14 Esses pontos vêm desenvolvidos abaixo nos itens 3.3 e 3.4.

Revista de Filosofia, Curitiba, v. 17 n.20, p. 99-124, jan./jun. 2005. 
pensamento ou de um saber, mas, além disso, e mais fundamentalmente, de assegurar que é justamente aí que surge essa verdade; ou seja, é especialmente na colocação de si como objeto do próprio pensamento, que reside a essência mesma do "ser um sujeito". Ao contrário do argumento filosófico ${ }^{15}$ que retoma o legado cartesiano para afirmar que não há como eu pensar em mim mesmo sem que eu seja nisso apenas objeto (cogitatum) e não mais sujeito (cogitans), Lacan, inserido numa interpretação do cogito que pode ser chamada de performativa, diz que o caráter existencial do sujeito fica preservado na dedução do sujeito transcendental ao menos todas as vezes em que penso "penso, logo sou". O argumento cartesiano limitaria minha existência (como sujeito) aos momentos em que resido em meu pensamento: “(...) esta proposição, eu sou, eu existo, é necessariamente verdadeira todas as vezes que a enuncio ou que a concebo em meu espírito" (DESCARTES, 1983, p. 92). No caso do psicanalista, ocorre ainda uma segunda limitação ao átimo que se situa entre o "logo sou" e um "sou isso" que seria subseqüente, mas que é sempre abortado, pois a afirmação de que sou se desvanece antes de poder se completar, incapaz que é de se sustentar em qualquer tipo de conteúdo positivo ${ }^{16}$.

Obviamente, o que Lacan preserva da operação cartesiana resume-se a esse ponto: suspensão de toda consideração da realidade em proveito de uma representação pura de si e qualificação do pensar e do falar como hábitat da certeza. Jamais poderia seguir o filósofo em seu processo de passagem pela inscrição da idéia de Deus no intelecto humano para fugir ao ceticismo e voltar a fundamentar a existência objetiva da realidade como idéia clara e distinta. Mais precisamente, ele só acompanha Descartes até o parágrafo quarto da segunda meditação, local da enunciação do cogito. Pois o passo imediatamente seguinte na determinação da possibilidade do conhecimento é assim expresso: "Mas não conheço ainda bastante claramente o que sou, eu que estou certo de que sou (...)” (DESCARTES, 1983, p. 92, grifo nosso). Aos olhos de Lacan, este "o que sou" representa a queda no substancialismo, na equiparação com a consciência e na objetivação do sujeito, a qual deve ser, mais que tudo, evitada.

15 Aqui Lacan parece estar se referindo especialmente a Sartre.

16 Essa impossibilidade de objetivação do inconsciente será posteriormente expressa da seguinte forma: "Tudo é permitido ao inconsciente, exceto articular: portanto sou." (Trecho do Seminário 14, A lógica do fantasma, citado por Boons-Grafé, 1997, p. 86). 
E, no intuito, fica ainda implícito que sua possibilidade está condicionada a um uso dos termos "pensamento" e "sujeito" num sentido bem distante do que eles poderiam possuir em Descartes. Quanto ao primeiro, basta, para salientar a discrepância, citar o seguinte trecho: "Pelo termo pensamento entendo todas aquelas coisas que, estando nós conscientes, ocorrem em nós, na medida em que há em nós uma consciência delas" (DESCARTES, apud LANDIM FILHO, 1997, p. 48). Quanto ao segundo, muito embora não seja ponto pacífico na interpretação do texto de Descartes, parece haver indícios de que a res cogitans, resultado do "eu penso, eu sou", não exaure o sentido do sujeito cartesiano. Enquanto em Descartes encontramos uma extensão do conceito de homem ao sujeito da imaginação e da sensibilidade, para além do sujeito do intelecto e da vontade como princípio de uma ação imanente à mente e, portanto, ao composto mente/corpo ${ }^{17}$, o argumento lacaniano repousa na restrição do sujeito à res cogitans como ponto evanescente de uma afirmação existencial. Ora, se a continuidade do cogito exige a certeza de si como união entre mente e corpo, é devido à passagem por Deus como garante da verdade e ao retorno à realidade objetiva desprovida de dúvida; passagem que, como vimos acima, não é acompanhada por Lacan.

Cabe considerar em mais detalhe o tipo de relação a si que é posta em cena com esse recurso ao cogito e aqui chegamos ao ponto de uma discussão controversa. Borch-Jacobsen considera que essa relação, a despeito da centralização do conceito de inconsciente, assume, na obra lacaniana, a forma de uma estrutura reflexiva da consciência de si. Há um seu ensaio (1991b) dedicado, mediante uma análise de como Freud e Lacan abordam o problema da hipnose, à defesa da hipótese de que o sujeito lacaniano do inconsciente seria, na verdade e em última análise, o sujeito da consciência. Para esse autor, se a divisão subjetiva tem por causa o fato do sujeito representar a si mesmo, isso significa que tal sujeito é o sujeito cartesiano, o que não passaria de uma forma de dizer que ele é o sujeito da consciência, apenas subtraído do momento da presença a si. Um dos argumentos utilizados para sustentar essa hipótese é a indicação de que Lacan constantemente denunciava as concepções do inconsciente que fizessem dele um mero outro da consciência

${ }^{17}$ Ver Landim Filho, 1997. “(...) Descartes parece sugerir que o homem, união da mente com o corpo, formaria um todo que seria considerado como o único sujeito de atribuição" (p. 55).

Revista de Filosofia, Curitiba, v. 17 n.20, p. 99-124, jan./jun. 2005. 
representativa. Mas, evocando o texto de Lacan, percebemos que essas suas afirmações não se direcionam no sentido desejado por Borch-Jacobsen, qual seja "(...) o inconsciente lacaniano não é senão o incon sciente da própria consciência representativa (...)." (1991b, p. 298) É, no entanto, bastante óbvio que Lacan, ao dizer que as formações do inconsciente não são o contrário dos fenômenos de consciência, não está com isso querendo consentir na homogeneidade dos lugares envolvidos em

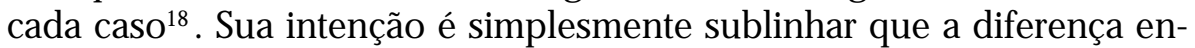
tre pré-consciente e inconsciente não é uma diferença de grau, mas de natureza, isto é, que o inconsciente não é algo não-consciente passível de se tornar consciente. Borch-Jacobsen faz com que, a uma identificação entre sujeito do inconsciente e sujeito de uma representação ou de uma relação a si se siga sua necessária equiparação ao sujeito da consciência ${ }^{19}$, como se essas locuções se enredassem reciprocamente, o que não parece proceder. Uma coisa não exclui a outra: a auto-representação é compatível com o cogito cego desde que seja entendida como equívoca. Dirá Lacan no Seminário 11, explicitando um pouco a relação de seu pensamento ao cogito: "Certamente, para toda representação é preciso um sujeito, mas esse sujeito não é jamais um sujeito puro. (...) Não há sujeito sem, em alguma parte, afânise do sujeito, e é nessa alienação, nessa divisão fundamental, que se institui a dialética do sujeito" (LACAN, 1988, p. 209). No que vemos que se trata de fato de um sujeito da representação; mas também que o desaparecimento do sujeito no momento mesmo da representação transforma em non sequitur a pretensão de ligá-lo à consciência e que, como se expressa Badiou, "o inconsciente é, no fundo, um nome para a separação irredutível entre identidade subjetiva e consciência.” (1997, p. 37, grifo nosso). O sujeito lacaniano é melhor pensado como uma subversão da representação mediante a negação; o que evita a reflexividade da consciência como conseqüência necessária. Aliás, poderíamos até dizer que o que interessa é justamente colocar em jogo a possibilidade de pensar, de um modo diferente do que fora articulado por Freud, a separação entre consciência e representação, quer dizer, uma representação inconsciente.

Enfim, trata-se simplesmente de perceber que, se o sujeito do inconsciente é o sujeito da consciência subtraído do momento da pre-

18 Ver Sessão VI do Seminário 2, por exemplo.

19 O sujeito "(...) só pode se relacionar a si (ou seja, estar consciente de si) separando-se de si (...)" (BORCH-JACOBSEN, 1991b, p. 309, grifo nosso). 
Ainda o sujeito - nota sobre o conflito determinação x subjetividade em Jacques Lacan

sença a si na medida em que só se representa em sua própria ausência, então ele não é mais o sujeito da consciência e, ao tomar-se por objeto, não se torna transparente a si mesmo...

Uma vez advertidos do problema apresentado no item anterior do presente artigo, não é difícil perceber o interesse visceral manifesto na manobra que passa por Descartes ${ }^{20}$. Ao apontar o sujeito como noção indispensável e deduzida filosoficamente, o deslize do filósofo, teria sido fazê-lo coincidir com a consciência ${ }^{21}$ e, conseqüentemente, igualar o sujeito que fala ao sujeito do qual se fala. Sua proposta é, em contraponto, desdobrar sujeito e objeto em enunciado e enunciação, procurando mostrar que quando eu falo de mim, o "eu" e o "mim" não possuem aí o mesmo referente. "Não se trata de saber se falo de mim conforme aquilo que sou, masse, quando falo de mim, sou o mesmo que aquele de quem falo" (LACAN, 1966, p. 517). E por aí pensar a existência de uma fala para além do eu, desenvolvendo o "(...) penso onde não sou, logo sou onde não penso" (LACAN, 1966, p. 517).

É pelo recurso a Descartes que Lacan faz com que o pensamento requeira um sujeito. Para isso, redefine o pensamento, desloca o "penso" e o "sou" da enunciação do cogito para lugares opostos e dispensa as meditações a partir do desenvolvimento da segunda. Noutras palavras, o que é preciso fazer com o cogito é, não uma despersonalização do pensamento - como ocorre em Sartre, por exemplo -, mas uma distinção entre consciência e sujeito e reconceber o sentido do ato de pensar através de uma leitura de Freud inspirada no estruturalismo que permitiria, por fim, uma nova subjetivação do pensamento, só que em outro nível.

20 Dessa forma, a problemática filosófica não é a causa da necessidade de uma remissão ao sujeito - como sugere Borch-Jacobsen (1991a) -, mas sua conseqüência. De acordo com Simanke (1994), a necessidade de reintrodução do sujeito teve origem na preocupação com a paranóia como fenômeno total; daí o recurso à filosofia, e não o contrário.

${ }^{21}$ Lacan dirá mais tarde, preservando esse raciocínio: “O cogito cartesiano (...) só faz denunciar melhor o que há de privilegiado no momento em que ele se apóia, e quão fraudulento é estender esse privilégio, para dele lhes dar um status, aos fenômenos providos de consciência" (1960b, p. 845) Verificar o antagonismo com Descartes: "Como todo ato supõe o sujeito do ato, todo ato de consciência supõe o sujeito de consciência. Mas ser sujeito do ato de consciência significa ser consciente e, por sua vez, ser consciente significa ser consciente de ser sujeito de seu ato de consciência. Portanto, quem efetua um ato de consciência 'sabe' que é sujeito desse ato, pois é impossível realizar um ato de consciência sem ter consciência de ser sujeito do ato." (LANDIM FILHO, 1997, p. 48)

Revista de Filosofia, Curitiba, v. 17 n.20, p. 99-124, jan./jun. 2005. 
Mas, afinal, como pode ser descrita, ao menos de modo aproximativo, essa estrutura de relação a si?

\title{
Esse sujeito garantido pelo cogito, que é ele?
}

\author{
"Melhor seria não haver nascido; \\ como segunda escolha bom seria \\ voltar logo depois de ver a luz \\ à mesma região de onde se veio." \\ (Sófocles, Édipo em Colono)
}

Descartes funciona como ponto de asserção da presença do sujeito na teoria. Mas isso, com efeito, em nada contribui para a dissolução do conflito determinismo versus subjetividade. Ele continua a ser uma questão a exigir novos encaminhamentos. Permanecemos diante da impossibilidade de compatibilizar um paradigma que providencia a exclusão do sujeito e a necessidade de especificar um uso desse termo que seja coerente e substancial. A pergunta com que precisamos nos confrontar agora é: por que Lacan insiste em dizer que o que sofre a determinação do significante é um sujeito?

De fato, se o significante tem alguma função, essa função é a de representar um sujeito submetido à sua operação: "Nossa definição do significante (não existe ou tra) é: um significante é aquilo que representa o sujeito para outro significante" (LACAN, 1960a/1966, p. 833). E o que fica aí subsumido, paradoxalmente, jamais poderá encontrar-se restrito ao que é meramente descrito pela linguagem.

O problema é, então, que à psicanálise interessa o sujeito nos dois sentidos da palavra. Segundo Abbagnano:

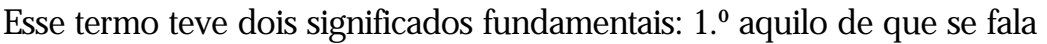
ou a que se atribuem qualidades ou determinações ou a que são inerentes qualidades ou determinações; $2 . \stackrel{0}{0}$ o eu, o espírito ou a consciência, como princípio determinante do mundo do conhecimento ou da ação, ou ao menos como capacidade de iniciativa em tal mundo. Ambos esses significados se mantêm no uso corrente do termo: o primeiro na terminologia gramatical e no conceito de sujeito como tema ou assunto do discurso; o segundo no conceito de sujeito como capacidade autônoma de relações ou de iniciativas, capacidade que é contraposta ao simples ser 'objeto' ou parte passiva de tais relações (2000, p. 929-30, grifo nosso). 
Para um saber atrelado a uma prática clínica, importa pensar 0 sujeito não apenas no sentido de destino de predicados, de algo que possa ser descrito em suas qualidades, mas também tal como na expressão "sujeito verbal", isto é, como lugar que, apesar de sofrer uma determinação transcendente, comporta a origem imanente da ação e do desejo. Diz Lacan no Seminário 3: "A noção de sujeito é correlativa da existência de alguém sobre o qual penso - Foi ele que fez isso" (1985, p. 119) O sujeito não pode aí ser visto apenas como a função de uma combinação de variáveis, mas precisa ser considerado também na medida em que se impõe numa cena de desejo, atentando-se ainda para o fato de que a realidade desse desejo não é abstrata, mas concreta e vital.

Examinemos uma passagem esclarecedora quanto a essa necessidade:

Essa redução [dos sintomas, na clínica] constatada demonstra uma dinâmica na qual o inconsciente se define como um sujeito efetivamente constitutivo, já que sustentava os sintomas em seu sentido antes que ele fosse revelado, e que é experimentado diretamente ao ser reconhecido na astúcia da desordem na qual o recalcado se compõe com a censura, no que, notemos de passagem, a neurose se aparenta à condição mais comum da verdade na fala e na escrita (1966, p. 333, grifos nossos).

Sob a pena de Lacan, vemos que é preciso pensar que o inconsciente se manifesta como um sujeito. É preciso pensá-lo devido à constatação de que há um ponto constitutivo do sentido não apenas dos sintomas, mas também do uso que fazemos da linguagem e que se exerce à revelia da consciência. Fica suposto um lugar de amarração do sentido e que o põe a funcionar. Quando se torna revelado o conluio entre 0 recalque e a censura, percebe-se que, se o indivíduo dele não tinha conhecimento, então esse sentido devia estar sendo sustentado, por assim dizer, por um outro alguém responsável pelas artimanhas das formações de compromisso. Certamente, a ordem de existência desse alguém não pode ser do tipo de uma substância e o "antes" que Lacan usa em seu texto deve ser entendido à luz de sua concepção do tempo: estava lá antes simplesmente porque precisou ser suposto pelo que aconteceu depois.

Mas, como, no nível de um saber - e se virtualmente todo determinismo requer a anulação dessa categoria -, falar de um sujeito que abriga uma singularidade ativa sem correr o risco de objetivá-lo, ou seja,

Revista de Filosofia, Curitiba, v. 17 n.20, p. 99-124, jan./jun. 2005. 
de desconhecê-lo ${ }^{22}$, e sem precisar retornar a uma perspectiva psicologista?

A resposta é guarnecida por Kojève. A primeira tentativa de Lacan no sentido de continuar preconizando uma forma de determinação subjetiva que se desvencilhe do psicologismo é apostar em que o predicado da sua identidade é a diferença de um vazio puro e ativo. Um sujeito empírico e implicado numa intencionalidade, mas que simultaneamente possibilita a quebra do vínculo com a idéia de uma interioridade psicológica é justamente a acepção encontrada na leitura que Kojève faz de Hegel, onde ele é potência de negação que, mediante o desejo, se manifesta na linguagem negando a realidade e inclusive a sua própria. $\mathrm{O}$ ser humano é na medida em que transcende a si mesmo nas coisas, negando-as, sem jamais retornar a uma sua identidade e encontrando-se apenas como um desejo puro que é a "revelação de um vazio". Na passagem para o desejo do desejo do outro, da mesma forma, ele só encontra sua própria não identidade a si, isto é, o desejo do outro é, igualmente, um nada.

Se o sujeito é totalmente produzido pela estrutura e portanto nela desaparece, torna-se plenamente conveniente pensá-lo como negatividade negadora, o que permite que ele não desapareça, ou melhor, que 0 status de sua presença seja esse desaparecimento positivado ${ }^{23}$ :

(...) tudo o que lhes ensino acerca da estrutura do sujeito, tal como tratamos de articulá-la a partir desta relação ao significante, converge para a emergência desses momentos de fading propriamente ligados a essa pulsação em eclipse do que não aparece senão para desaparecer e reaparece para desaparecer de novo, o que constitui a marca do sujeito como tal (LACAN, 1961/2, sessão de 24/01/62).

Trata-se de uma transposição de termos que, como vimos acima, não reclama uma substituição de quadros referenciais: o sujeito como negatividade é perfeitamente conciliável com o significante advindo da

${ }^{22}$ Em A coisa freudiana, Lacan, ao criticar a prática de análise da resistência por reforçar a postura objetivante do sujeito, ratifica: “É que a objetivação em matéria psicológica está submetida, em seu princípio, a uma lei de desconhecimento que rege o sujeito não apenas como observado, mas como observador" (1966, p. 419).

23 Badiou (1997) identifica a teoria lacaniana do sujeito a uma teoria do paradoxo - "(...) o gênio de Lacan foi fazer teoria do sujeito, como teoria do paradoxo." (p. 31) - na qual "um sujeito é um ponto paradoxal do ser" (p. 29)

Revista de Filosofia, Curitiba, v. 17 n.20, p. 99-124, jan./jun. 2005. 
lingüística estrutural. A ligação entre ambos é da ordem de uma dinâmica temporal. Antes dessa ligação, o sujeito não é nada - lembremos que a característica da existência de algo no mundo é, em Lacan, condicionada à conexão desse algo com a linguagem -; mas ele tampouco passa a ser após essa ligação, pois o significante cristaliza o sujeito, no que este perde sua condição ${ }^{24}$ : "O sujeito é esse surgimento que, justo antes, como sujeito, não era nada, mas que, a penas a parecido, se coagula em significante" (LACAN, 1988, p. 188). Há uma divisão do dizer e do dito na qual o sujeito se aliena ao mesmo tempo em que se mostra e a partir da qual ele pode ser concebido como um fenômeno diferido num vetor regressivo do tempo. Sempre que o significante procura designar o sujeito, ele o impessoaliza necessariamente, fazendo de sua tarefa um fracasso e, ao enunciar o "penso, logo sou" assinalado acima, o sujeito se anula, uma vez que se representa. $\mathrm{O}$ intenso desenvolvimento da temática da falta-aser não tem outro sentido: o ser do sujeito fica dessa forma reduzido a um instante temporal negativo espremido num sopro que só adquire alguma positividade mediante sua natureza de negação, seu caráter de pura transcendência. O significante como denominador do nada, nada requer de positivo do lado da subjetividade; ou melhor, a positividade da subjetividade fica circunscrita por sua realidade de negação. No terceiro ano do seminário, Lacan responde afirmativamente à seguinte pergunta de uma ouvinte: "Será que é entre Não sou nada e a morte, que deve se passar aquilo que pode substituir-se a um humanismo?” (1985, p. 269) Nada melhor para operacionalizar a determinação desse nada que é o sujeito do que um conceito de significante cuja característica essencial é a de não significar coisa alguma - nem um referente no mundo real, nem um significado. De acordo com Borch-Jacobsen, se Lacan tanto se preocupa em repetir, seguindo o estruturalismo, que o significante não representa nada, "(...) é porque lhe importa sobretudo estabelecer que ele representa (isto é, manifesta) esse 'nada' que é o sujeito” (1991b, p. 309). O sujeito, não sendo nada, não corre, pois, o risco de ser objetivado. Enfim, a noção lacaniana de sujeito relativa à década de 50 pode ser resu-

${ }^{24}$ Uma implicação direta desse raciocínio sobre a clínica - e que parece ser plena de conseqüências práticas - é que, ao falar de si no setting, o analisando está simultaneamente se anulando. Se falar das coisas é fazê-las desaparecerem, falar de si é fazer desaparecer a si mesmo. Para que o sujeito apareça no discurso é preciso que ele seja representado. Porém, ser representado equivale a ter cancelado seu modo positivo de existência.

Revista de Filosofia, Curitiba, v. 17 n.20, p. 99-124, jan./jun. 2005. 
mida na cláusula "o significante representa nada, nada que é o sujeito", na qual a oração principal é tributária do estruturalismo e a subordinada, do kojèvismo. Como explica Borch-Jacobsen (1991a),

De um lado da questão (...), essa tese diz o mesmo que a lingüística: o significante não representa nada, mas um outro significante. Mas doutro lado (aquele que realmente interessa a Lacan), essa tese também pode ser lida como afirmando que o significante representa nada, e que o significante (re)presenta o nada que o sujeito do desejo 'é'. Significantes não tencionam dizer nada (...), pelo que Lacan entende que todos eles dizem a mesma coisa - qual seja, o sujeito enquanto nada - e é por isso que eles são perfeitamente equivalentes exatamente em sua diferença (p. 186).

Pensar a negação como a definição da subjetividade possibilita ainda que se fale de um "sujeito verdadeiro", o que vem responder a três diferentes demandas internas à teoria: 1- se o simbólico é tão alienante quanto o imaginário, se o significante faz desaparecer o sujeito tanto quanto a imagem, por que isso não significa que o sujeito do inconsciente seja tão ilusónio quanto o eu? Ou seja, por que isso não significa um fiasco do projeto? Exatamente porque a alienação no simbólico preserva a positividade do sujeito como negação, indicando que sua verdade é o espaço vazio anterior à alienação. 0 revés da alienação simbólica é a preservação da essência do sujeito. $\mathrm{O}$ simbólico, ao mesmo tempo em que abriga 0 lado da determinação subjetiva, dá a ver que a verdade do sujeito é a negação, coisa que o eu é incapaz de fazer; ao contrário, o eu a dissimula. 2- 0 projeto de Lacan - até o Seminário 7, onde pode ser percebida uma nova equalização da questão - ainda se caracteriza pelo desejo de constituição de uma ciência do sujeito e, durante o período aqui analisado, não parece haver a possibilidade de uma ciência sem aspiração a uma verdade. 3- A idéia de um sujeito verdadeiro serve, além do mais, como garantia de que a análise não se qualifica por uma prática de sugestão ${ }^{25}$.

Entendida, dessa forma, a identidade do sujeito como a nãoidentidade a si, sobrariam duas alternativas para a caracterização da estrutura da relação a si:

25 “Não podemos pensar na experiência analítica como um jogo, um engodo, uma manigância ilusória, uma sugestão. Ela coloca em causa a fala plena [que é a fala verdadeira]" (LACAN, 1985, p. 129, tradução modificada).

Revista de Filosofia, Curitiba, v. 17 n.20, p. 99-124, jan./jun. 2005. 
1- Poderíamos tentar descrevê-la como uma estrutura irreflexiva - é o que faz Frank (1989), por exemplo: “A ex-centricidade do sujeito verdadeiro está ligada à impossibilidade de afirmar qualquer coisa a respeito de sua verdade (...) com os meios da 'captura de si que é a reflexão'” (p. 221). Mas tal escolha só conduz a uma aporia: não se vê como preservar o nome de sujeito a um fenômeno que suprime totalmente a reflexividade - ainda mais sendo ele envolvido numa problemática de reconhecimento por parte do outro e de si mesmo. Com efeito, Frank considera: ou o sujeito do inconsciente é reflexivo e aí seria tão problemático quanto o eu - ilusório, alienado etc. - ou é irreflexivo "(...) e não se vê então porque se possa considerá-lo um sujeito (...)” (1984, p. 233).

2- Uma outra forma, talvez mais interessante, de manobrar esse impasse é sustentar que o sistema da relação a si pode continuar a ser exposto como uma estrutura reflexiva. Porém, nesse caso, esse adjetivo terá que receber uma nova compreensão, diferente daquela ordinariamente presente no discurso filosófico, pois sua peculiaridade seria a ausência de uma apresentação do "si" à consciência. Uma reflexividade que, obviamente, não implique uma recaída na psicologia e nas filosofias da consciência e que não indica uma relação a si senão na medida em que institui um desvio que contorna necessariamente o nada. Retomando um pouco a crítica de Borch-Jacobsen discutida acima, este autor defendia, desdobrando seu argumento, a ocorrência de uma radicalização da aporia com que se defrontaram Leibniz, Kant, Fichte, Husserl e Sartre: a consciência transcendental só é consciência de si ao ser consciência do objeto, o que significa que ela só pode se representar diante de si mesma (efetivar sua reflexividade) como um objeto ou, no caso de Lacan, como um significante. Percebemos, a essa altura, que se trata justamente do contrário porque, na teoria lacaniana, esse momento de objetivação do sujeito encontra-se impossibilitado. Uma estrutura de relação a si certamente exige que o sujeito se coloque numa distância em relação a si mesmo como ponto de apreensão do fenômeno. Mas, para Lacan, o que se apresenta na distância assim tomada não pode deixar de ser um nada; o "si" em questão sempre se desloca quando o sujeito se engaja nesse empreendimento.

Podemos considerar que os desenvolvimentos imediatamente posteriores da teoria têm lugar para, de certa forma, continuar a suprimir esse impasse ligado à necessidade de formular uma reflexividade de tipo diferenciado, supressão que vai passar a se fazer acompanhar de uma relativização do ideal de cientificidade para a psicanálise.

Revista de Filosofia, Curitiba, v. 17 n.20, p. 99-124, jan./jun. 2005. 


\section{A falta no Outro e o passo seguinte}

Trata-se agora apenas de fornecer um índice do outro lado da tentativa de fazer conviverem determinação e subjetividade, ou seja, aquilo que se passa do lado da estrutura ${ }^{26}$. E é aqui que podemos avançar um pouco um certo esclarecimento da especificidade dessa reflexividade diferenciada.

Na medida em que Lacan começa a desenvolver a idéia de um furo no Outro - isto é, na estrutura subjetivada -, passa a se tornar possível a formulação de uma determinação não-total do sujeito. $\mathrm{O}$ objeto a surgirá posteriormente (durante os anos 60) como a sobra atualizada de uma estrutura faltante e funcionará como ponto vazio em que o sujeito, também vazio, porém existente, como resto efetivo (e não somente como epifenômeno) do assujeitamento à estrutura, pode exercitar sua faculdade de reconhecimento. Como esclarece _i_ek em seu O mais sublime dos histéricos:

(...) ora, a falta no Outro quer dizer que há um resto, uma inércia nãointegrável no Outro, o objeto a, e o sujeito pode evitar a alienação total justamente na medida em que se coloca como correlato desse resto $\$ \diamond \mathrm{a}$. Dessa maneira, podemos conceber um sujeito que difere do eu, lugar do desconhecimento imaginário: um sujeito que não se perde no 'processo sem sujeito' da combinação estrutural (1991, p. 78).

O objeto a, sendo algo não-integrável pelo sujeito, encarna 0 vazio em que ele pode se reconhecer e se substitui, em função, ao significante que, em resposta ao desejo de reconhecimento do sujeito, só o reenviava a outro significante, moto-perpétuo. Bloqueia o movimento puramente negativo do sujeito ao acrescentar-lhe uma segunda negação: a negação de uma inércia inapreensível na qual a idéia de subjetividade passa a se somar a algo capaz de responder pelo concreto da fantasia e pela singularidade do desejo que nada possui de abstrato."O sujeito, a negatividade pura, o movimento absoluto da mediação, não pode chegar a o ser-para-si, à sua existên cia efetiva, a não ser tornando a se encarnar num momento absolutamente inerte, não-subjetivo" (_I_EK, 1991, p. 97). ${ }^{27}$

\footnotetext{
${ }^{26} \mathrm{O}$ desenvolvimento e a problematização mais largos deste ponto constituirão matéria de um outro trabalho.

27 Cf., ainda a esse respeito, os desenvolvimentos de Safatle (2004).
} 
Por que o desejo deve ter um objeto, ainda que não seja objeto do desejo, mas sua causa? Por que não pode ser desejo de nada, como toda a teoria lacaniana levaria a deduzir? Simplesmente porque de fato desejamos objetos, amamos, direcionamos um investimento psíquico em alvos específicos e comumente deveras rígidos, insubstituíveis. Mesmo que Lacan pense que "o universo é uma falha na pureza do Não-Ser" (1960a/1966, p. 819), não pode desprezar este fato. Ele afinal precisou “(...) emprestar um pouco de 'matéria' àquele inapreensível sujeito do significante e, ao mesmo tempo, um pouco de corpo e objetividade ao seu desejo" (BORCH-JACOBSEN, 1991a, p. 229). Eis o que confere ao objeto a sua centralidade no lacanismo (Lacan o considerou a sua invenção propriamente dita): a possibilidade de garantir uma dimensão - talvez possamos dizê-lo - existencial para a teoria, uma forma de pensar 0 desejo com a pulsão, com o corpo e com a fantasia. Que poderiam, afinal, num exercício clínico, uma concepção do sujeito como negatividade que só se manifesta no seu desaparecer e uma noção do desejo como puro em essência, sem objeto? Se o sujeito é em fading - o que não é aparecendo, o que aparece não sendo -ele é, portanto, de qualquer forma, pensado como algo que aparece e esse aspecto positivo de sua manifestação só pode residir na produção da fantasia, de uma cena que fixa o desejo em sua consistência singular, enfim, de um objeto que, embora não funcione para a satisfação do desejo, provoca o seu movimento e serve de aparato para o reconhecimento de alguma identidade para esse sujeito tão fugaz: "É preciso um Da para o desejo pois ele deseja se fazer reconhecer, isto é, exibir-se fora, à luz de um lugar público" (BORCH-JACOBSEN, 1991b, p. 308). Sem isso, a construção teórica do sujeito resumir-se-ia à sua vertente transcendental de puro não-ser oriunda da forma como Kojève o pensou. Isto é, sem o objeto a como contraponto do sujeito puro, estaria ausente da noção de sujeito qualquer raiz que ele pudesse cavar no empírico, qualquer relação plausível que ele pudesse tornar efetiva com uma prática clínica sem a qual o discurso lacaniano exatamente na sua especificidade de discurso psicanalítico (tal como entendido pelo próprio Lacan) não poderia sequer existir.

Se o sujeito "desaparecente" só se relaciona a si mediante 0 contorno de um objeto faltante cujo conteúdo inerte é apenas a positivação do seu vazio, então é exatamente aí que podemos entrever a possibilidade de uma reflexividade peculiar, aquela que, ao apresentar a facticidade do reconhecimento num objeto vazio, indica que o único suces-

Revista de Filosofia, Curitiba, v. 17 n.20, p. 99-124, jan./jun. 2005. 
so que este pode almejar é o reconhecimento da impossibilidade do reconhecimento. Encontramos essa trilha percorrida por_i_ek que, no que segue, bem desvela a idéia:

Aqui se anuncia, ao mesmo tempo, a dimensão de uma certa reflexividade que escapa à dimensão tradicional da reflexão própria da subjetividade filosófica. (...) A citada positivação da impossibilidade implica, ao contrário, um tipo inteiramente diferente da inversão reflexiva: seu desafio é antes, para o sujeito, reconhecer, na impossibilidade de se apropriar do Coração do Outro, uma condição positiva que define seu estatuto de sujeito. A virada consiste, pois, numa mudança radical de perspectiva: é seu fiasco - o fracasso de seu esforço de se apropriar do conteúdo substantivo oposto, de penetrar no Coração do Outro - que inclui o sujeito na substância, em seu Outro (1991, p. 113, primeiro grifo nosso).

Vemos que a contrapartida do sujeito como negação é a falta no Outro e que a necessidade desta última noção para a dinâmica interna da teoria é que, com ela, o vínculo sujeito/estrutura passa a ser visto como relação de negação a negação e não mais como uma relação de mão única na qual a determinação partia da estrutura para sobrepujar totalmente o sujeito. Então o problema talvez se configure mais ou menos assim: para fugir do impasse do estruturalismo (desaparecimento do sujeito), Lacan reforça Kojève (o sujeito como negação inobjetivável); para fugir do impasse do kojèvismo (um sujeito puro, descolado do empírico do desejo), ele se volta para o objeto a na fantasia. Isso não significa que o sujeito deixe de ser negatividade, mas que ele passa a possuir uma positividade como correlato de sua existência negativa. É nesses termos que pode ser inspecionada a ultrapassagem do estruturalismo na obra lacaniana; seu início pode ser situado exatamente no momento em que Lacan começa a falar da falta no Outro (1999), momento de transição que ainda pode ser qualificado de estruturalista - haja em vista a abordagem do complexo de Édipo aí encontrada - mas que já anuncia, pelo que vimos acima, um esgotamento desse referencial.

\section{Conclusão - A amarração dos três termos}

Na tentativa de conciliar ciência e subjetividade, Lacan, ao longo dos desdobramentos de sua teoria durante os anos 50, atribui um 
sinal diacrítico ao sujeito (a negação acompanhada do caráter evanescente) e outro à estrutura (a noção de falta no Outro), ambos absolutamente necessários às chances de coerência da teoria. Um sujeito inobjetivável e uma estrutura inobjetivante: a originalidade de uma combinação entre negatividade e um Outro determinante, porém descompletado, é a fórmula encontrada, no período que tomamos para análise, para dissolver o impasse do desaparecimento do sujeito na ciência. Nisso, o manejo converge para três termos de uma equação indecomponível: estruturalismo, subjetividade e kojèvismo. Eles se encontram implicados mutuamente sob um laço necessário: não é possível sustentar o estruturalismo sem o sujeito e sem Kojève: a conseqüência disso seria uma sociologia sem parentesco com uma prática clínica e um discurso sobre a subjetividade na medida em que ela não fosse, exatamente, uma subjetividade; não é possível sustentar o sujeito abrindo mão do estruturalismo e do kojèvismo: o efeito seria uma psicologia à qual estaria vedada qualquer aspiração à ciência, isto é, um discurso do tipo doxa e uma indesejável aproximação com o contingente e com a obscuridade de uma interioridade psicológica; enfim, não é possível sustentar Kojève sem o estruturalismo: o resultado seria uma antropologia filosófica incapaz de lidar com uma noção de inconsciente e de aspirar a alguma relação com a ciência. No entanto, no momento mesmo em que essa articulação encontra seu lugar, o próprio conflito determinação versus subjetividade começa a ser, de certa forma, despriorizado na teoria, tendo início um encaminhamento ético da experiência psicanalítica. E interessante será indagar a medida da relação desse novo desenvolvimento com a negação no sujeito e a falta na estrutura.

\section{Referências}

ABBAGNANO, N. Dicionário de filosofia. 4. ed. São Paulo, SP: Martins Fontes, 2000.

BADIOU, A. Onde estamos com a questão do sujeito? Letra freudiana: Colóquio Psicanálise e Filosofia -Sujeito e Linguagem, Rio de Janeiro, v. 16, n. 22, p. 27-44, 1997.

BAIRRÃO, J. M. Aquém do princípio da psicanálise: Lacan crítico da Psicologia. Revista Olhar, São Carlos, v. 2, n. 3, p. 31-40, maio, 2000.

Revista de Filosofia, Curitiba, v. 17 n.20, p. 99-124, jan./jun. 2005. 
BOONS-GRAFÉ, M. C. Ou eu não penso, ou eu não sou. Letra freudiana: Colóquio Psicanálise e Filosofia -Sujeito e Linguagem, Rio de Janeiro, v.16, n. 22, p. 81-93, 1997.

BORCH-JACOBSEN, M. Lacan: the absolute master. Stanford, California: Stanford University, 1991a.

BORCH-JACOBSEN, M. Les alibis du sujet (Lacan, Kojève, et al). In: LACAN avec les philosophes. Paris: Albin Michel, 1991b.

DESCARTES, R. Meditações. In: Os pensadores. São Paulo, SP: Abril Cultural, 1983.

DOSSE, F. História do estruturalismo: o campo do signo, 1945/1966. São Paulo, SP: Ensaio, 1993. v. 1.

FRANK, M. Qu'est-ce que lê neo-structuralisme? De Saussure et LéviStrauss a Foucault et Lacan. Paris: Cerf, 1989.

KOJÈVE, A. Introduction à la lecture de Hegel. 6. ed. Paris: Gallimard, 1947.

LACAN, J. Da psicose paranóica em suas relações com a personalidade. Rio de Janeiro, RJ: Forense Universitária, 1987.

La famille. 1938b. In: ENCYCLOPÉDIE Française: La vie mentale. Paris: Larousse, 1938. v. 8.

Au-delà du "principe de realité. In: LACAN, J.; MIRON, Murray S. Ecrits 1. Paris: Sevil, 1966.

Propos sur la causalité psychique. In: LACAN, J.; MIRON, Murray S. Écrits 1. Paris: Sevil, 1966.

L'agressivité en psychananlyse. In: LACAN, J.; MIRON, Murray S. Ecrits 1. Paris: Sevil, 1966.

O Seminário. Livro I: os escritos técnicos de Freud 1953-1954. Rio de Janeiro, SP: Jorge Zahar, 1986.

. La chose freudienne. In: LACAN, J.; MIRON, Murray S. Écrits 1. Paris: Sevil, 1966.

. Le séminaire sur "La lettre volé". In: LACAN, J.; MIRON, Murray S. Ecrits 1. Paris: Sevil, 1966. 
Ecrits 1. Paris: Sevil, 1966.

Variantes de la cure-type. In: LACAN, J.; MRON, Murray S.

O Seminário: Livro II: o eu na teoria de Freud e na técnica da psicanálise 1954-1955. Rio de Janeiro: Jorge Zahar, 1985.

O Seminário. Livro III: as psicoses 1955-1956. 2. ed. Rio de Janeiro, RJ: Jorge Zahar, 1988.

. L'instance de la lettre dans l'inconscient ou la raison depuis Freud 1957. In: LACAN, J.; MIRON, Murray S. Écrits 1. Paris: Sevil, 1966.

O Seminário: Livro V: as formações do inconsciente 1957-1958. Rio de Janeiro, RJ: Jorge Zahar, 1999.

- Subversion du sujet et dialectique du désir dans l'inconscient freudien 1960a. In: LACAN, J.; MIRON, Murray S. Écrits 1. Paris: Sevil, 1966.

. Position de l'inconscient 1960b. In: LACAN, J.; MRON, Murray S. Ecrits 1. Paris: Sevil, 1966.

- Seminário IX: a identificação. Seminário inédito 1961-1962. Buenos Aires: Paidós, 1988.

. O Seminário: Livro XI: os quatro conceitos fundamentais da psicanálise 1964. 2. ed. rev Rio de Janeiro, RJ: Jorge Zahar, 1985.

. Intervention sur l'exposé de Michel Foucault “Qu'est ce qu'un auteur?". Bibliothèque Lacan. Bulletin de la Société française de philosophie, n. 3, p. 104, 1969. Disponível em: http://www.ecolelacanienne.net/pastoutlacan60.php.

LANDIM FILHO, R. A questão do sujeito em Descartes. Letra freudiana: Colóquio Psicanálise e Filosofia -Sujeito e Linguagem, v. 16, n. 22, p. 47-58, 1997.

SAFATLE, V. Estética do real: pulsão e sublimação na reflexão lacaniana sobre as artes. In: IANNINI, G. et al (Orgs.). O tempo, o objeto e o avesso: ensaios de filosofia e psicanálise. Belo Horizonte: Autêntica, 2004.

Revista de Filosofia, Curitiba, v. 17 n.20, p. 99-124, jan./jun. 2005. 
SALES, L. S. O valor epistemológico do diálogo de Jacques Lacan com o estruturalismo. Psychê: revista de psicanálise, São Paulo, v. 7, n. 11, p. 39-58, jan./jun. 2003.

SIMANKE, R. T. Lacan: subjetividade e psicose. Discurso, São Paulo, n. 23, p.149-175, 1994.

. Metapsicologia lacaniana: os anos de formação. São Paulo,SP: Discurso, 2002.

I EK, S. O mais sublime dos histéricos: Hegel com Lacan. Rio de Janeiro,RJ: Jorge Zahar, 1991.

Recebido em: Received in: 22/02/ 2005 Aprovado em: Approved in: 23/03/2005 